\title{
Effect of oncological treatment on serum adipocytokine levels in patients with stage II-III breast cancer
}

\author{
TEOMAN COSKUN $^{1}$, FUNDA KOSOVA $^{2}$, ZEKI ARI $^{3}$, ASLAN SAKARYA $^{1}$ and YAVUZ KAYA ${ }^{1}$ \\ ${ }^{1}$ Department of General Surgery, Faculty of Medicine; ${ }^{2}$ School of Health; \\ ${ }^{3}$ Department of Biochemistry, Faculty of Medicine, Celal Bayar University, 45030 Manisa, Turkey
}

Received May 20, 2015; Accepted March 8, 2016

DOI: $10.3892 / \operatorname{mco} .2016 .815$

\begin{abstract}
Adipose tissue-derived hormones (adipocytokines), such as adiponectin, leptin, resistin and visfatin, and the pancreatic hormone insulin, have been suggested to play a role in carcinogenesis. We therefore hypothesized that the oncological treatment of breast cancer may alter the serum levels of these adipocytokines and insulin. In this study, we aimed to compare the serum levels of adipocytokines and insulin between the pre- and post-treatment period in patients with breast cancer. In this prospective study, 20 consecutive patients with stage II and III breast cancer underwent breast-conserving surgery or total mastectomy and/or axillary dissection. The patients received adjuvant chemotherapy and radiotherapy, if necessary. Blood samples were obtained during the preoperative period and postoperatively after completion of the adjuvant therapy. There was no statistically significant difference between the pre- and post-treatment levels of visfatin, adiponectin and leptin. However, the serum insulin and resistin levels and insulin resistance were found to be statistically significantly increased following treatment $(\mathrm{P}<0.05)$. Post-treatment resistin levels were positively correlated with insulin resistance $(\mathrm{r}=0.45, \mathrm{P}<0.05)$. Therefore, oncological treatment of stage II and III breast cancer did not affect visfatin, adiponectin and leptin levels, but statistically significantly increased resistin levels and insulin resistance. In addition, the post-treatment resistin levels were positively correlated with insulin resistance, suggesting that resistin may be involved in the development of insulin resistance in breast cancer patients following treatment.
\end{abstract}

\section{Introduction}

Obesity and estrogens have long been implicated in the pathogenesis of breast cancer (1). Adipose tissue is known to

Correspondence to: Professor Teoman Coskun, Department of General Surgery, Faculty of Medicine, Celal Bayar University, Uncubozköy, 45030 Manisa, Turkey

E-mail: coskunt@hotmail.com

Key words: breast carcinoma, adipocytokine, resistin, insulin be a site of peripheral aromatization of adrenal androgens to estrogens, which in turn induce mitogenic activity in breast tissue. Additionally, obesity is strongly associated with insulin resistance characterized by hyperinsulinemia, which is also suggested to play a mitogenic role in the development of breast cancer (2).

Apart from aromatization of adrenal androgens, adipose tissue secretes a variety of proteins, referred to as adipocytokines, that may also play a role in breast carcinogenesis. Multiple studies have been designed to elucidate the association between breast cancer and adipocytokines, such as leptin, adiponectin, visfatin and resistin. Although there are conflicting results in the literature, high leptin $(3,4)$, visfatin (5) and resistin $(6,7)$ levels and low adiponectin (8) levels appear to be associated with increased breast cancer risk.

Since adipocytokines are hormones, their levels in the blood may be affected by several factors. It is of interest whether the tumor mass itself or the various factors secreted into the bloodstream by the tumor affect the blood levels of adipocytokines. A recent study demonstrated that leptin is produced by tumor cells, suggesting that removal of the tumor may decrease the circulating levels of this adipocytokine (9). Thus, we hypothesized that the levels of adipocytokines may be altered by surgical removal of the tumor mass and medical treatment of the disease. If so, these cytokines may be used as markers during the follow-up after breast cancer treatment. The aim of this study was to compare the pre- and post-treatment serum levels of leptin, adiponectin, visfatin, resistin and insulin in patients with stage II and IIIA breast cancer.

\section{Patients and methods}

Patients. A total of 20 consecutive patients with operable stage II and III breast cancer were included in this prospective study. Patients with metastatic disease, diabetes mellitus and chronic medical conditions, such as obstructive pulmonary disease and congestive heart disease, were not included in the study. All the patients were newly diagnosed, histologically confirmed, adult patients with breast cancer, who were treated at the Department of General Surgery, Faculty of Medicine, Celal Bayar University (Manisa, Turkey) between 2008 and 2012. The study protocol was approved by the Ethics Committee of the Faculty and informed consent was obtained from each patient prior to inclusion in the study. The levels 
of adiponectin, leptin, visfatin, resistin, glucose and insulin in the patients' blood were compared between the preoperative period and at 6 months after surgery.

A total of 9 patients had stage II and 11 patients had stage IIIA disease. The surgical treatment was breast-conserving surgery $(n=4)$ or total mastectomy $(n=16)$. The patients underwent axillary dissection if metastatic axillary lymph nodes were identified during the preoperative examination or sentinel lymph node biopsy. A total of 5 patients were premenopausal at diagnosis. None of the patients had received chemotherapy or radiotherapy prior to surgery. All the patients received adjuvant chemotherapy and 15 patients received radiotherapy following chemotherapy.

Demographic, clinical and anthropometric data were collected upon recruitment. Staging was performed according to the 2009 American Joint Committee on Cancer staging system (10). Body mass index (BMI) was calculated as weight $(\mathrm{kg})$ divided by the square of height $\left(\mathrm{m}^{2}\right)$ prior to and following treatment for breast cancer. Insulin resistance (IR) was calculated using the homeostatic model assessment index (HOMA) as follows: (HOMA-IR) $=$ [fasting glucose (mmol/l) x fasting insulin (mU/l)/22.5] (11).

Blood samples were obtained from the antecubital vein on the day prior to surgery between 8:00 and 9:00 am after an overnight fast, and at 6 months after surgery. All the patients completed their oncological treatment including chemo- and radiotherapy within this 6-month period. For adiponectin, leptin, resistin, visfatin and insulin studies, the blood was immediately transferred into a tube containing EDTA and centrifuged. The serum samples were then maintained at $-80^{\circ} \mathrm{C}$ until further analysis. All the samples from each patient were run in the same assay. Serum adiponectin, leptin, visfatin and resistin levels were measured by ELISA kits (Millipore Corp., Billerica, MA, USA). Serum insulin was measured by an auto-analyzer (niCel DxI 800; Beckman Coulter, Brea, CA, USA).

Statistical analysis. The Wilcoxon signed-rank test was used for the analysis of biomedical data. Two-tailed probability values were calculated. The correlation between post-treatment resistin levels and insulin resistance was assessed by the Pearson's correlation coefficient. $\mathrm{P}<0.05$ was considered to indicate a statistically significant difference. Statistical analysis of the data was performed using SPSS statistical software, version 17.0 for Windows (SPSS, Chicago, IL, USA).

\section{Results}

Patient characteristics. The mean age of the patients was 51 years (range, 26-71 years). Of the 20 patients, 13 were considered as obese $\left(\mathrm{BMI}>30 \mathrm{~kg} / \mathrm{m}^{2}\right)$. Oncological treatment did not alter the BMI values of the patients $(\mathrm{P}>0.05)$.

Pre-and post-treatment serum adipocytokine and insulin levels. There was no statistically significant difference between the pre- and post-treatment levels of visfatin, adiponectin and leptin. However, the serum insulin and resistin levels and insulin resistance were found to be statistically significantly increased following treatment $(\mathrm{P}<0.05)$ (Table I and Fig. 1).

In addition, the post-treatment resistin levels were positively correlated with insulin resistance $(\mathrm{r}=0.45, \mathrm{P}<0.05)$.

\section{Discussion}

Adipose tissue is a complex and metabolically active endocrine organ. Adipocytes, as well as the non-adipocyte fraction of the adipose tissue, synthesize and secrete several hormones, such as leptin, visfatin, resistin and adiponectin, referred to as adipocytokines.

In brief, leptin regulates the body's fat stores, induces cell proliferation, promotes angiogenesis and inhibits cellular apoptosis (8). The role of visfatin and resistin in carcinogenesis is not as clear as that of leptin. A basic research study revealed that visfatin may contribute to breast cancer etiopathogenesis by augmenting cell proliferation through stimulation of cell cycle progression and by increasing the expression of genes that are crucial for angiogenesis and metastasis (12). Resistin is secreted from adipocytes and, particularly, from monocytes in the adipose tissue and is suggested to be involved in inflammatory processes, including obesity-related subclinical inflammation, atherosclerosis, cardiovascular disease and rheumatic disease (13); its role in malignant tumors has not been yet established, but it was suggested to be involved in carcinogenesis. Adiponectin has been found to exert an antiproliferative effect on various breast cancer cell lines (14) and has been suggested to be an anticarcinogenic hormone.

Although the results reported in the literature are conflicting, it appears that the circulating levels of leptin, visfatin and resistin are increased and the levels of adiponectin are decreased in patients with breast cancer compared with those in healthy controls. However, the cause of the differences in adipocytokine levels between patients and controls has not been fully elucidated. Adipocytokines secreted by the tumor mass itself or the biologically active substances secreted by the tumor, which may stimulate or inhibit the production of adipocytokines by the adipose tissue, may be the cause of this difference. If so, removal of the tumor will obviously decrease the levels of visfatin, leptin and resistin and increase the levels of adiponectin in cancer patients.

To the best of our knowledge, this is the first study to evaluate the effect of surgical and medical treatment of breast cancer on the circulating levels of adipocytokines in the blood. In one of our recent studies, we investigated the effect of the surgical removal of the tumor on adipocytokine levels in patients with colorectal cancer and observed a statistically significant decrease in only the adiponectin levels following treatment (15); serum ghrelin, resistin and visfatin levels, however, were found to be unchanged, despite cancer treatment. In the present study, despite radical treatment, we did not identify any significant differences between the pre- and post-treatment levels of visfatin, leptin and adiponectin in breast cancer patients. Only resistin levels were found to be significantly increased following treatment. It appears that the tumor mass itself exerted no or little effect on the levels of visfatin, leptin and adiponectin in our study.

The main difference between the two measurements of resistin levels in our study is the oncological treatment that the patients received, which included chemotheraphy and radiotherapy. Resistin, as previously mentioned, is closely associated with various inflammatory processes. Radiation is one of the main causes that activate inflammation in the tissues undergoing radiotherapy. The ionization events and free 
Table I. Comparison between pre- and post-treatment levels of adiponectin, leptin, visfatin, resistin, glucose and insulin in the serum of 20 breast cancer patients.

\begin{tabular}{lccccr}
\hline Timepoint & $\begin{array}{c}\text { Adiponectin } \\
(\mathrm{ng} / \mathrm{ml})\end{array}$ & $\begin{array}{c}\text { Leptin } \\
(\mathrm{ng} / \mathrm{ml})\end{array}$ & $\begin{array}{c}\text { Visfatin } \\
(\mathrm{ng} / \mathrm{ml})\end{array}$ & $\begin{array}{c}\text { Resistin }{ }^{\mathrm{a}} \\
(\mathrm{ng} / \mathrm{ml})\end{array}$ & $\begin{array}{r}\text { Glucose } \\
(\mathrm{mg} / \mathrm{dl})\end{array}$ \\
\hline Pretreatment & $80.8 \pm 28.7$ & $6.0 \pm 4.7$ & $1.1 \pm 0.9$ & $3.5 \pm 1.0$ & $\begin{array}{r}\text { Insulin }^{\mathrm{b}} \\
(\mu \mathrm{g} / \mathrm{ml})\end{array}$ \\
Post-treatment & $92.1 \pm 44.2$ & $6.3 \pm 3.9$ & $1.0 \pm 0.8$ & $4.9 \pm 1.9$ & $106.9 \pm 11.9$ \\
\hline
\end{tabular}

${ }^{\mathrm{a}} \mathrm{P}=0.028 ;{ }^{\mathrm{b}} \mathrm{P}=0.006$. Values are presented as mean \pm standard deviation.

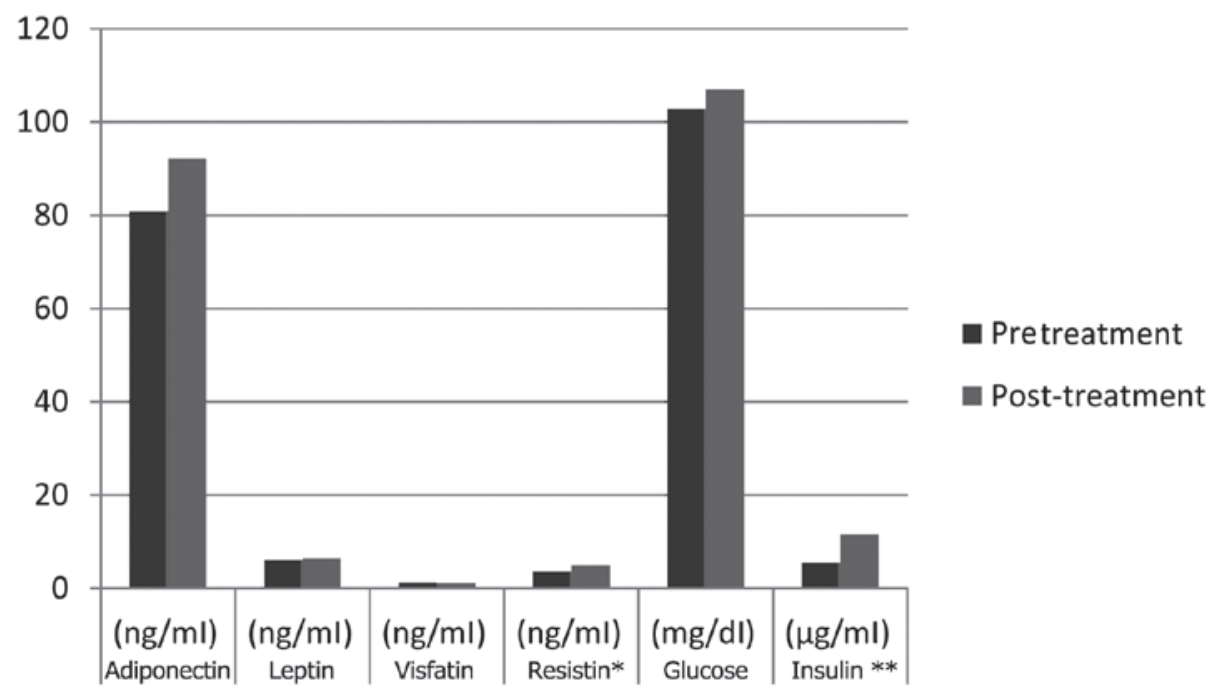

Figure 1. Pre- and post-treatment levels of adiponectin, leptin, visfatin, resistin, glucose and insulin in the serum of breast cancer patients. . $\mathrm{P}=0.028$; *"P=0.006.

radicals produced by radiation cause damage to vital cellular components. DNA damage from radiation commonly leads to cell death during the first cell division, or within the first few divisions following irradiation, leading to inflammation (16). Additionally, radiation activates various cellular signalling pathways (17) that lead to the expression and activation of proinflammatory and profibrotic cytokines (18-20), vascular injury (21) and activation of the coagulation cascade (22). These changes may be involved in the development of oedema, inflammatory responses and the initiation of wound-healing processes. A total of $75 \%$ of the patients received radiotherapy in our study. The blood samples for adipocytokine analysis in our patients were collected immediately following completion of the radiation therapy, as determined by the study design. Therefore, we hypothesized that radiotherapy-induced inflammation may be the cause of the increase in resistin levels in the patients in our study. However, since this is only a hypothesis, prospective randomized studies are required to determine the effect of radiotherapy on the serum resistin levels of breast cancer patients.

In the literature, it has been reported that the risk of breast cancer is increased in association with obesity and diabetes, both of which are characterized by increased insulin resistance, with consequent increases in the circulating levels of insulin and glucose $(23,24)$. Insulin promotes cell proliferation $(25,26)$ and enhances breast tumor growth in animal models $(27,28)$. Therefore, we may hypothesize that high levels of insulin or glucose may be involved in the etiology of breast cancer. The few prospective studies to date that have directly investigated the association between fasting glucose and insulin levels and the risk of incident breast cancer have yielded conflicting results (29-32). The aim of our study was not to determine whether high insulin levels induce breast cancer, but rather to identify any changes in fasting insulin levels between pre- and post-treatment measurements. There was a statistically significant increase in insulin levels and insulin resistance during the post-treatment period in our patients, whereas there was no change in glucose levels.

Certain factors may have induced an increase in the insulin levels in our study. One of these factors may be the metabolic disturbance observed following adjuvant breast cancer therapy. Guinan et al (33) investigated the alterations in metabolic and insulin resistance parameters from the time of breast cancer diagnosis to completion of adjuvant breast cancer treatment, and reported that patients with breast cancer, without other serious comorbidities, demonstrated a significant deterioration in their metabolic profiles, characterized by increases in fasting insulin and associated insulin resistance. Despite the observed increased fasting insulin levels, fasting glucose remained unchanged in their study, suggesting that insulin resistance had developed, but that the pancreas was able to compensate sufficiently to maintain glucose homeostasis (34). There were also no differences regarding the weight and BMI of the patients following completion of the adjuvant therapy. 
All these results are consistent with the results of our study. The increase in post-treatment insulin levels and insulin resistance was suggested by Guinan et al (33) to be due to obesity, age and estrogen deficiency. Obesity is the most common underlying cause of insulin resistance. It is commonly reported that breast cancer patients frequently gain weight during adjuvant treatment for breast cancer (35). However, we observed no differences in body weight or BMI in our patients following adjuvant treatment. The other factor that may have contributed to the increase in post-treatment insulin levels and insulin resistance is estrogen deficiency. Insulin resistance is rarely observed in premenopausal women, but emerges with the onset of menopause due to estrogen deficiency (36). Adjuvant chemotheraphy and tamoxifen treatment may induce ovarian ablation in young patients, leading to early-onset menopause and related metabolic changes (37). Only 5 premenopausal women were included in our study, whose menopausal status could be affected by oncological treatment. Therefore, the effect of chemotherapy-induced menopause on insulin levels in our study would be minimal, if any.

Another cause that may increase insulin levels and insulin resistance in patients who undergo oncological treatment may be the increased levels of resistin during the post-treatment period. Resistin was first identified in 2001 and considered to contribute to insulin resistance. The administration of resistin to healthy mice impaired glucose tolerance and insulin action, and antibody against resistin improved blood sugar levels and insulin action (38). We observed statistically increased resistin levels in our patients during the post-treatment period. In addition, the increase in resistin levels was positively correlated with the increase in insulin resistance in our study. These findings suggest that high resistin levels induced by the oncological treatment may be the cause underlying the development of metabolic disturbances, such as insulin resistance, in treated cancer patients.

In conclusion, removal of the tumor mass and adjuvant oncological treatment did not alter the serum levels of visfatin, adiponectin or leptin in patients with stage II-III breast cancer in our study. However, the resistin levels were found to be increased. Radiotheraphy-induced inflammation may be the cause underlying the increase in resistin levels during the post-treatment period in our study. The effect of radiotherapy on resistin levels following cancer treatment should be further investigated in well-designed studies. Post-treatment resistin levels were also found to be positively correlated with insulin resistance in our study, which, in turn, suggests that high resistin levels may have affected insulin resistance in our breast cancer patients following treatment.

\section{References}

1. Stoll BA: Upper abdominal obesity, insulin resistance and breast cancer risk. Int J Obes Relat Metab Disord 26: 747-753, 2002.

2. Macciò A, Madeddu C and Mantovani G: Adipose tissue as target organ in the treatment of hormone-dependent breast cancer: New therapeutic perspectives. Obes Rev 10: 660-670, 2009.

3. Chen DC, Chung YF, Yeh YT, Chaung HC, Kuo FC, Fu OY, Chen HY, Hou MF and Yuan SS: Serum adiponectin and leptin levels in Taiwanese breast cancer patients. Cancer Lett 237: 109-114, 2006.

4. Wu MH, Chou YC, Chou WY, Hsu GC, Chu CH, Yu CP, Yu JC and Sun CA: Circulating levels of leptin, adiposity and breast cancer risk. Br J Cancer 100: 578-582, 2009.
5. Dalamaga M, Archondakis S, Sotiropoulos G, Karmaniolas K, Pelekanos N, Papadavid E and Lekka A: Could serum visfatin be a potential biomarker for postmenopausal breast cancer? Maturitas 71: 301-308, 2012.

6. Kang JH, Yu BY and Youn DS: Relationship of serum adiponectin and resistin levels with breast cancer risk. J Korean Med Sci 22: 117-121, 2007.

7. Dalamaga M, Sotiropoulos G, Karmaniolas K, Pelekanos N, Papadavid E and Lekka A: Serum resistin: A biomarker of breast cancer in postmenopausal women? Association with clinicopathological characteristics, tumor markers, inflammatory and metabolic parameters. Clin Biochem 46: 584-590, 2013.

8. Jardé T, Perrier S, Vasson MP and Caldefie-Chézet F: Molecular mechanisms of leptin and adiponectin in breast cancer. Eur J Cancer 47: 33-43, 2011.

9. Tessitore L, Vizio B, Jenkins O, De Stefano I, Ritossa C, Argiles JM, Benedetto $\mathrm{C}$ and Mussa A: Leptin expression in colorectal and breast cancer patients. Int J Mol Med 5: 421-426, 2000.

10. Edge SB, Byrd DR, Compton CC, Fritz AG, Greene FL and Trotti A (eds): AJCC Cancer Staging Manual. 7th edition. Springer, New York, NY, 2010.

11. Matthews DR, Hosker JP, Rudenski AS, Naylor BA, Treacher DF and Turner RC: Homeostasis model assessment: Insulin resistance and beta-cell function from fasting plasma glucose and insulin concentrations in man. Diabetologia 28: 412-419, 1985.

12. Kim JG, Kim EO, Jeong BR, Min YJ, Park JW, Kim ES, Namgoong IS, Kim YI and Lee BJ: Visfatin stimulates proliferation of MCF-7 human breast cancer cells. Mol Cells 30: 341-345, 2010.

13. Filková M, Haluzík M, Gay S and Senolt L: The role of resistin as a regulator of inflammation: Implications for various human pathologies. Clin Immunol 133: 157-170, 2009.

14. Wang Y, Lam JB, Lam KS, Liu J, Lam MC, Hoo RL, Wu D, Cooper GJ and $\mathrm{Xu}$ A: Adiponectin modulates the glycogen synthase kinase-3beta/beta-catenin signaling pathway and attenuates mammary tumorigenesis of MDA-MB-231 cells in nude mice. Cancer Res 66: 11462-11470, 2006.

15. Kosova F, Coskun T, Kaya Y, Kara E and Ari Z: Adipocytokine levels of colon cancer patients before and after treatment. Bratisl Lek Listy 114: 394-397, 2013.

16. Thompson LH and Suit HD: Proliferation kinetics of $\mathrm{x}$-irradiated mouse L cells studied WITH TIME-lapse photography. II. Int J Radiat Biol Relat Stud Phys Chem Med 15: 347-362, 1969.

17. Dent P, Yacoub A, Contessa J, Caron R, Amorino G, Valerie K, Hagan MP, Grant S and Schmidt-Ullrich R: Stress and radiation-induced activation of multiple intracellular signaling pathways. Radiat Res 159: 283-300, 2003.

18. Chen Y, Williams J, Ding I, Hernady E, Liu W, Smudzin T, Finkelstein JN, Rubin P and Okunieff P: Radiation pneumonitis and early circulatory cytokine markers. Semin Radiat Oncol 12 (Suppl 1): 26-33, 2002.

19. Rubin P, Johnston CJ, Williams JP, McDonald S and Finkelstein JN: A perpetual cascade of cytokines postirradiation leads to pulmonary fibrosis. Int J Radiat Oncol Biol Phys 33: 99-109, 1995.

20. Fu XL, Huang H, Bentel G, Clough R, Jirtle RL, Kong FM, Marks LB and Anscher MS: Predicting the risk of symptomatic radiation-induced lung injury using both the physical and biologic parameters $\mathrm{V}_{30}$ and transforming growth factor $\beta$. Int $\mathrm{J}$ Radiat Oncol Biol Phys 50: 899-908, 2001.

21. Paris F, Fuks Z, Kang A, Capodieci P, Juan G, Ehleiter D, Haimovitz-Friedman A, Cordon-Cardo C and Kolesnick R: Endothelial apoptosis as the primary lesion initiating intestinal radiation damage in mice. Science 293: 293-297, 2001.

22. Hauer-Jensen M, Kong FM, Fink LM and Anscher MS: Circulating thrombomodulin during radiation therapy of lung cancer. Radiat Oncol Investig 7: 238-242, 1999.

23. Kaaks R: Nutrition, hormones, and breast cancer: Is insulin the missing link? Cancer Causes Control 7: 605-625, 1996.

24. Vona-Davis L, Howard-McNatt M and Rose DP: Adiposity, type 2 diabetes and the metabolic syndrome in breast cancer. Obes Rev 8: 395-408, 2007.

25. Chappell J, Leitner JW, Solomon S, Golovchenko I, Goalstone ML and Draznin B: Effect of insulin on cell cycle progression in MCF-7 breast cancer cells. Direct and potentiating influence. J Biol Chem 276: 38023-38028, 2001.

26. Ish-Shalom D, Christoffersen CT, Vorwerk P, Sacerdoti-Sierra N, Shymko RM, Naor D and De Meyts P: Mitogenic properties of insulin and insulin analogues mediated by the insulin receptor. Diabetologia 40 (Suppl 2): S25-S31, 1997. 
27. Shafie SM and Hilf R: Insulin receptor levels and magnitude of insulin-induced responses in 7,12-dimethylbenz(a) anthracene-induced mammary tumors in rats. Cancer Res 41: 826-829, 1981

28. Shafie SM and Grantham FH: Role of hormones in the growth and regression of human breast cancer cells (MCF-7) transplanted into athymic nude mice. J Natl Cancer Inst 67: 51-56, 1981.

29. Mink PJ, Shahar E, Rosamond WD, Alberg AJ and Folsom AR: Serum insulin and glucose levels and breast cancer incidence: The atherosclerosis risk in communities study. Am J Epidemiol 56: 349-352, 2002.

30. Eliassen AH, Tworoger SS, Mantzoros CS, Pollak MN and Hankinson SE: Circulating insulin and c-peptide levels and risk of breast cancer among predominately premenopausal women. Cancer Epidemiol Biomarkers Prev 16: 161-164, 2007.

31. Gunter MJ, Hoover DR, Yu H, Wassertheil-Smoller S, Rohan TE, Manson JE, Li J, Ho GY, Xue X, Anderson GL, et al: Insulin, insulin-like growth factor-I, and risk of breast cancer in postmenopausal women. J Natl Cancer Inst 101: 48-60, 2009.

32. Kabat GC, Kim M, Caan BJ, Chlebowski RT, Gunter MJ, Ho GY, Rodriguez BL, Shikany JM, Strickler HD, Vitolins MZ, et al: Repeated measures of serum glucose and insulin in relation to postmenopausal breast cancer. Int J Cancer 125: 2704-2710, 2009.
33. Guinan E, Connolly EM, Healy LA, Carroll PA, Kennedy MJ and Hussey J: The development of the metabolic syndrome and insulin resistance after adjuvant treatment for breast cancer. Cancer Nurs 37: 355-362, 2014

34. American Diabetes Association: Diagnosis and classification of diabetes mellitus. Diabetes Care 35 (Suppl 1): S62-S69, 2010.

35. Demark-Wahnefried W, Peterson BL, Winer EP, Marks L, Aziz N, Marcom PK, Blackwell K and Rimer BK: Changes in weight, body composition, and factors influencing energy balance among premenopausal breast cancer patients receiving adjuvant chemotherapy. J Clin Oncol 19: 2381-2389, 2001.

36. Carr MC: The emergence of the metabolic syndrome with menopause. J Clin Endocrinol Metab 88: 2404-2411, 2003.

37. Kaaja RJ: Metabolic syndrome and the menopause. Menopause Int 14: 21-25, 2008.

38. Steppan CM, Bailey ST, Bhat S, Brown EJ, Banerjee RR, Wright CM, Patel HR, Ahima RS and Lazar MA: The hormone resistin links obesity to diabetes. Nature 409: 307-312, 2001. 